\title{
a REVISTA TEMAS EM EDUCAÇÃO
}

\section{UM ESTUDO DE CASO}

\section{DE ALUNAS COM}

DEFICIÊNCIA

NEUROMOTORA:

UMA ANÁLISE DE

SUA VIVÊNCIA

ESCOLAR EM UMA

INSTITUIÇÃO DE

ENSINO REGULAR

\section{NA ÓTICA DE SEUS}

PROFESSORES

\author{
Stela Marques [*] \\ Luciene Cangussu [**]
}

[*] Doutora em Educação. Professora Ajunta e

Pesquisadora em Educação na Pontifícia

Universidade Católica de Minas Gerais (PUC-

Minas)

E-mail: sm.pucminas@gmail.com

ORCID: https://orcid.org/0000-0001-7810-1977

[**] Pedagoga. Professora vinculada a Prefeitura

Municipal de Esmeralda, Minas Gerais.

E-mail: lucienecangussu@hotmail.com

ORCID:https://orcid.org/0000-0003-0942-0661

\section{RESUMO}

O trabalho aqui apresentado busca compreender como é a vida escolar de duas alunas com deficiência neuromotora, na ótica dos profissionais da educação que as acompanham diariamente em uma escola da rede municipal da cidade de Esmeraldas, em Minas Gerais. A escolha do tema se deu pelo interesse em compreender como os educadores do Ensino Fundamental I enfrentam os desafios de trabalhar com alunas com necessidades educacionais especiais, sendo que uma apresentava sequelas de mielomeningocele, e a outra, sequelas de hipóxia perinatal. Para realização deste estudo foram feitas inúmeras leituras, observações e entrevistas. Foram selecionadas as profissionais da educação que mantinham contato mais próximo com estas alunas. Percebeu-se, com este estudo, o despreparo e a insegurança das profissionais em trabalhar com crianças com este tipo de limitações, assim como também foi possível perceber a "exclusão" das mesmas em um ambiente que deveria ser de todos.

Palavras-chave: Educação inclusiva.

Prática Docente. Professor de Apoio. 


\section{INTRODUÇÃO}

Este trabalho apresenta um estudo de caso da vida escolar de duas alunas com deficiência neuromotora, que estudam em uma classe comum da rede municipal da cidade de Esmeraldas, em Minas Gerais. Este estudo buscou conhecer como é desenvolvida a prática dos profissionais da educação e quais recursos metodológicos eles utilizam para viabilizar a promoção da aprendizagem das alunas com deficiência, uma vez que, de acordo com Toledo e Martins (2009), somente boa vontade não é suficiente para garantir uma educação de qualidade, é preciso muito mais que boas intenções.

Desse modo, não é apenas o professor do Atendimento Educacional Especializado, (AEE) que deve ser preparado para trabalhar com o aluno com deficiência, mas todos os profissionais da educação, pois o estudante não é aluno exclusivo de uma determinada sala de aula, mas sim de toda a escola.

Contudo, a formação continuada do professor adequada é importante para que ele possa, não apenas inserir os alunos na escola, mas integrá-los ao convívio social e promover a construção de saberes através de práticas e recursos pedagógicos que viabilizam essa inserção do aluno com deficiência nas salas comuns do ensino regular.

De acordo com Carneiro (2007), a inclusão é um desafio para a escola comum, pois para que os alunos com deficiência usufruam o direito de ter uma educação de qualidade é preciso que as escolas aprimorem suas práticas a fim de atender as diferenças.

Nesse sentido, Carvalho (2004) afirma que é preciso entender que a proposta da educação inclusiva não foi pensada apenas para um determinado grupo de alunos, mas sim para todos, indistintamente. Além disso, a escola tem que se tornar um espaço onde os alunos possam conviver desenvolvendo sentimentos sadios em relação ao outro e a si mesmo.

A educação inclusiva é um processo que visa a participação de todos os estudantes, sem nenhuma forma de preconceito ou discriminação, nos estabelecimentos de ensino regular. "Trata-se de uma reestruturação da cultura, da prática e das políticas vivenciadas nas escolas de modo que estas respondam à diversidade dos alunos" (RODRIGUES, 2008, p. 21). 
De acordo com Rodrigues (2008), a inclusão escolar de todos os educandos, não somente dos que possuem deficiências, altas habilidades ou que tenham qualquer distúrbio de aprendizagem, deve partir de uma abordagem humanística, democrática, que percebe o sujeito e suas individualidades, objetivando o crescimento, a interação social e o aprazimento de todas as pessoas independente de sua cultura, de sua situação física, psicológica ou socioeconômica.

Nas últimas décadas muito se tem debatido sobre a inclusão de alunos com deficiências em classes comuns do ensino regular, no entanto, é comum encontrar em escolas públicas professores que se dizem não estar preparados para trabalhar com esse alunado. Alguns desses docentes se sentem inseguros e afirmam não ter clareza de como trabalhar com esses estudantes e como avaliar sua aprendizagem e seu desenvolvimento.

Pretende-se compreender a vivência escolar de duas alunas: uma com sequelas de mielomeningocele e hidrocefalia e a outra com sequelas causadas por hipóxia perinatal, ambas no $5^{\circ}$ ano, em uma classe comum de uma escola pública.

Nos últimos anos, devido às políticas de inclusão, o número de alunos com deficiências nas escolas regulares em classes comuns aumentou expressivamente. De acordo com os dados do Censo Escolar de 2015 “em 1998, cerca de 200 mil pessoas estavam matriculadas na educação básica, sendo apenas 13\% em classes comuns. Em 2014, eram quase 900 mil matrículas e 79\% delas em turmas comuns". De acordo com Clarete dos Santos (2015), diretora de Políticas de Educação Especial da Secretaria de Educação Continuada, "se considerarmos somente as escolas públicas, o percentual de inclusão sobe para 93\% em classes comuns” (PORTAL BRASIL, 2015, p 01.).

De acordo com Toledo e Martins (2009), para que haja uma inclusão efetivamente de alunos com NEE nas escolas é preciso que os professores tenham uma nova visão sobre essa população, que haja um acolhimento e que se paute em princípios éticos, solidários e equânimes. É fundamental direcionar um novo olhar sobre esses alunos, observando suas potencialidades, para que eles possam desenvolver com autonomia suas capacidades.

A mudança para uma educação inclusiva de fato requer professores habilitados, especializados e dispostos a desenvolver uma educação de qualidade pautada no respeito à diversidade cultural. Ainda conforme Toledo e Martins (2009), é preciso que o professor em exercício reflita sobre sua formação e seu preparo para receber esses alunos, uma vez que a escola é para todos, e, independente se os professores estão preparados ou não, esses estudantes continuarão chegando. 
No entanto, de acordo com Minetto (2012) mesmo os professores com formação superior se mostram inseguros quanto à inclusão de alunos com deficiência em salas comuns do ensino regular, pois o "novo" às vezes assusta, e não saber como lidar com a diversidade em sala de aula envolve aspectos pedagógicos, crenças valores e sentimentos: "O professor precisa identificar suas percepções sobre sua prática pedagógica para buscar soluções conscientes e aprimorar suas competências nas áreas que realmente estejam defasadas sejam elas teóricas, práticas ou relacionais" (MINETTO, 2012, p.48).

Ainda conforme esta mesma autora, acreditar que somente o professor está despreparado é uma maneira simplista de ver a problemática da inclusão, pois muitas escolas precisam rever seus procedimentos de ensino e sua organização como um todo.

Contudo, é interessante observar que, se o número de matrículas de alunos com deficiência vem aumentando em classes comuns, e os docentes julgam não estar preparados para trabalhar com esse alunado com NEE, como os profissionais da educação e/ou a escola, estão lidando com essa realidade?

\section{CONCEITUAÇÃO BÁSICA}

A mielomeningocele é uma malformação congênita da coluna vertebral do feto que ocorre durante a $3^{\circ}$ e a $5^{\circ}$ semana de gestação, que pode ser diagnosticada nos exames de pré-natal como o ultrassom. A mielomeningocele ocorre por uma falha no fechamento do tubo neural do embrião. Os bebês com esta malformação apresentam um quadro clínico variável, sendo os mais comuns a anencefalia e a espinha bífida (AGUIAR et al., 2003):

\footnotetext{
A anencefalia é a ausência completa ou parcial do cérebro e do crânio. A espinha bífida é um defeito de fechamento ósseo posterior da coluna vertebral. O defeito pode ser recoberto por pele essencialmente normal (espinha bífida oculta), ou associar-se com uma protrusão cística, podendo conter meninges anormais e líquido cefalorraquidiano - meningocele; ou elementos da medula espinhal e/ou nervos-mielomeningocele (AGUIAR et al., 2003, p. 01).
}

De acordo com Godoi (2006), a mielomeningocele ocorre quando as vértebras da coluna não se fecham como deveriam, expondo assim a medula, desse modo o bebê nasce com uma bolsa nas costas que deve ser corrigida após o nascimento. Godoi (2006) e Aguiar et al. (2003) concordam que bebês com mielomeningocele podem apresentar problemas neurológicos como a hidrocefalia: 
A criança com menigocele ou mielomeningocele pode apresentar incapacidades crônicas graves, como paralisia de membros, hidrocefalia, deformação de membros e da coluna vertebral, disfunção vesical, intestinal, sexual e dificuldade de aprendizagem, com risco de desajuste psicossocial (p.1).

Segundo Godoi (2006) “A hidrocefalia é causada por um problema na circulação do líquor entre o cérebro e a medula, acumulando-se na cabeça e empurrando o cérebro contra o crânio" (GODOI, 2006, p 81). Conforme esta mesma autora essa pressão sofrida pelo cérebro pode acarretar alguns prejuízos e afetar o desenvolvimento cognitivo dessa criança.

Já a hipóxia perinatal ou neonatal é a diminuição do oxigênio no cérebro da criança, podendo ocorrer antes ou durante o parto. Quando há somente uma diminuição do oxigênio a criança costuma se recuperar e, portanto não apresenta sequelas, no entanto, quando há uma ausência de oxigênio por um período maior de tempo, poderão ocorrer lesões severas no sistema nervoso, causando sérias lesões cerebrais comprometendo o desenvolvimento neuromotor do indivíduo ou até a morte após o nascimento (ABCMED, 2013, p. 1):

\footnotetext{
Se o problema for solucionado rapidamente, o feto costuma recuperar sem que se produzam complicações. Do contrário, as complicações mais dramáticas do sofrimento fetal são as lesões cerebrais. Elas podem ser difusas e de pouca severidade e ocasionar problemas de comportamento e atraso no desenvolvimento psicomotor do indivíduo ou serem mais extensas e mais severas e ocasionar paralisia cerebral infantil, epilepsia e retardo mental. As lesões encefálicas graves podem levar à morte do feto durante o parto ou logo após o nascimento.
}

Segundo Greggio e Costa, (2008) as crianças que sofreram hipóxia podem apresentar atrasos no desenvolvimento psicomotor e problemas de comportamento, isso quando a lesão cerebral foi de pouca severidade, porém nos casos em que a lesão cerebral tenha sido mais extensa e severa poderá causar paralisia cerebral infantil, epilepsia e retardo mental.

\section{Sequelas de mielomeningocele e hipóxia perinatal}

De acordo com Assis e Martinez (2011, p. 247), as possíveis sequelas encontradas em alunos com mielomeningocele são: comprometimentos na locomoção, ausência de sensibilidade abaixo do nível da lesão medular, alterações ortopédicas como pés tortos, congênitos e alterações 
nos quadris prejudicando, portanto a marcha. Segundo essas autoras, a hidrocefalia é outra sequela presente em cerca de $90 \%$ dos casos de indivíduos com mielomeningocele, "o que implica no crescimento rápido e anormal da cabeça" (ASSIS; MARTINEZ, 2011, p. 247).

A criança com hidrocefalia pode apresentar retardo no desenvolvimento neuromotor, problemas visais e auditivos e também disfunções intestinais, com o intestino neurogênico que de acordo com Furlan (2005), quando ocorre uma lesão medular, e dependendo da gravidade dessa lesão, o sistema nervoso não consegue controlar a função intestinal normalmente, desse modo o indivíduo pode vir a não ter controle dos esfíncteres causando incontinência urinaria e fecal, esses alunos.

A criança que sofreu hipóxia dependendo do grau e da parte do cérebro lesionada poderá apresentar atrasos no seu desenvolvimento psicossocial, retardo no desenvolvimento motor e mental (GREGGIO; COSTA, 2008).

Os alunos com sequelas dessas lesões são públicos da educação especial, contudo para que esses alunos tenham garantidos não só o acesso, mas sua permanência na escola comum é preciso que sejam feitas adaptações curriculares no intuito de promover sua participação no contexto escolar.

\section{Adequações Curriculares para alunos com deficiências}

As Adaptações Curriculares consistem, de acordo com Carvalho (2008), em modificações espontaneamente realizadas pelos professores e nas estratégias que são intencionalmente realizadas para dar respostas às necessidades de cada aluno, principalmente os que têm Necessidades Educacionais Especiais (NEE). Segundo essa mesma autora, trata-se de um planejamento em que se propõem estratégias de atuação em busca da inclusão de todos os educandos, respeitando as individualidades e reconhecendo as características de cada um, para que possamos adequar à proposta curricular em prol da participação de todos, no processo de aquisição do conhecimento. No entanto, não se trata de fazer um novo currículo, mas sim, adaptar o currículo existente fazendo ajustes de ensino, nas temporalidades e nas práticas de avaliação, de modo que possa oferecer de maneira igualitária, as oportunidades de construir conhecimentos a cada sujeito respeitando suas individualidades: 
O aluno é um sujeito do processo de ensino-aprendizagem; suas diferenças individuais, traduzidas como diferentes características e necessidades pessoais, devem ser conhecidas e respeitadas para a organização do ensino, com vistas à qualidade de sua aprendizagem. (CARVALHO, 2008, p.111)

Diante do exposto, os indivíduos com sequelas de mielomeningocele e hipóxia conforme descritas, terão necessidades de adaptações curriculares para que possam ter igualdade de oportunidades no acesso e permanência nas escolas comuns.

\title{
METODOLOGIA
}

A metodologia escolhida para a realização desta pesquisa foi a de cunho qualitativo, pois os pressupostos desta abordagem estão coerentes com o objeto deste estudo. Nesse sentido, Chizzotti (2010, p 79) ressalta:

\begin{abstract}
A abordagem qualitativa parte do fundamento de que há uma relação dinâmica entre o mundo real e o sujeito, uma interdependência viva entre o sujeito e o objeto, um vínculo indissociável entre o mundo objetivo e a subjetividade do sujeito. O conhecimento não se reduz a um rol de dados isolados, conectados por uma teoria explicativa; o sujeito observador é parte integrante do processo de conhecimento e interpreta os fenômenos, atribuindo-lhes um significado. O objeto não é um dado inerte e neutro; está possuído de significado e relações que sujeitos concretos criam em suas ações (CHIZZOTTI, 2010, p 79).
\end{abstract}

Devido a inúmeros fatores que envolvem a educação inclusiva, principalmente o que ocorre dentro da escola e para que haja uma maior compreensão da temática, decidiu-se como procedimento metodológico realizar um estudo de caso.

O estudo de caso, segundo Carvalho (2008), é:

\begin{abstract}
Uma estratégia de pesquisa utilizada em ciências sociais, e tem como objetivo desenvolver uma investigação empírica (fora de laboratório) de um fenômeno social que se deseja compreender em sua complexidade, conhecendo mais profundamente suas características e o contexto em que se manifesta, para que se possam implementar as ações necessárias (CARVALHO, 2008, p 132).
\end{abstract}

De acordo com Goldenberg $(2009$, p.34) "no estudo de caso, as diferenças internas e os comportamentos desviantes da média são revelados e não escondidos atrás de uma suposta homogeneidade". Nessa perspectiva, a observação da vivência escolar das alunas possibilita a compreensão das relações que os sujeitos, alunos e professores estabelecem com o processo de 
inclusão dos alunos com NEE na sala de aula, permitindo um conhecimento mais profundo da escola e dos processos de individualização das crianças. (GOLDENBERG, 2009, p.34)

Diante disso realizou-se inicialmente uma pesquisa documental onde se analisou os laudos das alunas para saber quais eram seus diagnósticos médicos. Em seguida, foi realizada uma observação não participante na escola e na sala de aula, em busca de conhecer o espaço e a vivência das alunas. Foram realizadas também, entrevistas não estruturadas para complementar os dados obtidos. As entrevistas foram realizadas com os seguintes sujeitos: duas professoras regentes, a professora de apoio das alunas com deficiências e a supervisora pedagógica da escola. A escolha desses participantes se deve ao fato delas serem as pessoas que estão envolvidas diretamente na vida escolar das alunas.

Inicialmente foi usado um roteiro, no entanto, no decorrer da entrevista foram sendo agregadas outras perguntas que se fizeram necessárias. Algumas entrevistas foram gravadas e transcritas com as devidas autorizações das participantes, outras, porém não puderam ser gravadas, tendo sido registradas manualmente pela entrevistadora.

A princípio, a intenção era entrevistar também as alunas, no entanto, a família da aluna 01 não autorizou e a família da aluna 02 não se manifestou a respeito da sua participação. Por esse motivo, as alunas em questão não foram entrevistadas, sendo realizada, portanto, apenas a observação de suas rotinas escolares.

A realização da pesquisa envolveu três etapas, sendo elas: o planejamento do estudo, o contato com a escola e seus envolvidos, e por fim, a realização do estudo de caso que se compreendeu entre: observações, entrevistas e análise de dados.

O planejamento do estudo de caso se definiu entre: do que seria pesquisado, a seleção dos participantes de acordo com o perfil estabelecido, a determinação do tempo destinado ao trabalho de campo e por fim em posse dos dados da observação foi formulado as perguntas e realizadas as entrevistas para confirmar e esclarecer as hipóteses.

Para coletar os dados foi selecionada uma escola pública de Ensino Fundamental no município de Esmeraldas em Minas Gerais. Foi definido que as atividades realizadas na escola teriam duração de três semanas, podendo se estender por mais tempo caso necessário.

O estudo foi realizado no turno vespertino tendo sido realizadas nesse período as seguintes atividades: observações da rotina das alunas com NEE nos espaços comuns da escola e na sala de 
aula, a prática das professoras e, posteriormente, entrevistas com duas professoras regentes, uma professora de apoio e a supervisora pedagógica.

A pesquisa foi realizada em uma Instituição de Ensino da Rede Municipal da cidade de Esmeraldas. A escola está situada em uma comunidade carente, com uma população socioeconômica baixa. A instituição é organizada em três turnos que atendem do $1^{\circ}$ ano ao $9^{\circ}$ ano do ensino fundamental. Atende também as turmas da EJA (Educação de Jovens e adultos).

Quanto à sua estrutura física, a escola possui 12 salas de aula, um pequeno refeitório, uma cantina, uma sala de professores, uma secretaria, uma sala de diretoria, sete sanitários, sendo um com acessibilidade que é utilizado pelos funcionários e alunos com deficiência. Há ainda um laboratório de informática, porém nunca foi utilizado devido à falta de profissionais capacitados para trabalhar com os materiais disponíveis (computadores). A escola possui uma quadra de esportes coberta, mas rampa que dá acesso à quadra é muito alta e não possui corrimão de segurança desse modo, os alunos com mobilidade reduzida não conseguem acessá-la sem ajuda. No entorno da quadra há uma arquibancada com degraus. Há também uma pequena biblioteca, com poucos livros, porém não há neste ambiente, como em nenhum outro na escola, móveis adaptados para pessoas com NEE.

A escola não oferece recursos como sala ambiente, sala de leitura ou sala de recursos, para atender os alunos com NEE. Não há na escola uma equipe pedagógica que ofereça suporte para atendimento a todas as crianças com deficiências. $\mathrm{O}$ atendimento especial é dado apenas aos alunos com NEE que possuem laudo médico, e assim sendo, apenas estes terão um professor de apoio permanente em sala de aula.

Quanto à sala de aula observada, foi uma turma do $5^{\circ}$ ano do Ensino Fundamental I. A sala possui 31 alunos sendo duas alunas com NEE. Nesta sala ficavam a professora regente e a professora de apoio. As alunas com NEE centro do interesse desta pesquisa ficavam sentadas nas primeiras cadeiras próximas à porta e a professora de apoio sentava-se entre as duas alunas. Não há mobiliários nem materiais adaptados para atender as necessidades específicas destas alunas.

Para realizar a coleta de dados foram selecionadas as profissionais que, no momento da pesquisa, tinham um contato mais próximo com as alunas. Todas as entrevistadas possuíam formação em Pedagogia. Sendo assim, foram entrevistadas a coordenadora pedagógica da instituição, duas professoras regentes e uma professora de apoio. As alunas observadas estudam no 
$5^{\circ}$ ano e ambas possuem NEE, têm a mesma idade, são atendidas pela mesma professora de apoio e foram aqui identificadas como AL01 e A102.

A AL01 tinha dez anos de idade no momento da realização desta pesquisa. Segundo seu laudo médico, ela possui diagnóstico de mielomeningocele e hidrocefalia compensada com válvula de derivação ventriculoperintoneal. Apresenta também em associação ao quadro, bexiga e intestino neurogênico, em decorrência dessa condição faz uso de fraldas.

Segundo Furlan et al. (2005, p. 153), “intestino neurogênico é uma condição que afeta o processo corporal para o armazenamento e a eliminação de resíduos sólidos de alimentos não digeridos" (FURLAN et al., 2005, p. 153). Conforme esses autores quando ocorre uma lesão medular, dependendo da gravidade dessa lesão, o sistema nervoso não consegue controlar a função intestinal normalmente.

Esta aluna faz uso também de órtese tornozelo-pé, que segundo Medeiros et al. (2013), é um dispositivo que é utilizado para manter o tornozelo e o pé em posição estável e melhorar o alinhamento dos mesmos. A aluna não faz uso de muletas, porém, como tem dificuldades na marcha, está sempre sustentada pela professora de apoio.

Ainda de acordo com o laudo médico, esta aluna apresenta também uma defasagem entre sua idade cronológica e o seu processo pedagógico. Devido a isso, apresenta dificuldades em matemática e memorização. A estudante esquece com muita facilidade o que aprende. Contudo, ela é alfabetizada lê e escreve com desenvoltura e se expressa muito bem. Todavia, ela interage pouco com os colegas e conversa apenas com a professora de apoio e com a outra aluna com NEE.

A aluna AL02 estava com dez anos quando foi realizada esta pesquisa, de acordo com seu laudo médico, possui atraso no desenvolvimento neuropsicomotor devido a hipóxia perinatal, apresenta movimentos estereotipados de braços e cabeça, fala com dificuldade, faz acompanhamento multidisciplinar na APAE com fonodiólogo e fisioterapeuta. A aluna é muito quieta, fica muito encolhida na cadeira, não se relaciona com os demais alunos da sala, interage apenas com a AL01 e a professora de apoio.

Ela é alfabetizada, porém, devido ao comprometimento da sua coordenação motora fina tem dificuldade em segurar o lápis, por isso tem problemas de escrita. A aluna não se expressa muito bem por meio da fala, sendo assim quando está com algum problema, ela apresenta movimentos característicos para chamar a atenção da professora de apoio. 
Uma das professoras regentes, PR1, era formada em Pedagogia, fez pós-graduação em Docência do Ensino Superior, é concursada e foi nomeada para esta escola no início de ano de 2016. Exerce a profissão docente há 12 anos. A outra professora regente, PR2, era formada em Pedagogia, trabalha nesta escola há oito anos e exerce a docência há 15 anos. Já a professora de apoio, PA, formou-se em Pedagogia em 2010, é especializada em Educação Especial e trabalha como professora de apoio nesta escola há três anos. Participou ainda deste estudo a supervisora pedagógica, SP, formada em Pedagogia, fez especialização em Ensino da Matemática. Trabalha na Prefeitura de Esmeraldas nesta função há oito anos.

\section{O QUE NOS REVELOU ESTE ESTUDO}

As observações da rotina das alunas duraram cerca de três semanas e durante esse período verificou-se que a AL01 é levada à escola de carro pelos pais e sempre chegava após a entrada dos demais alunos. A professora de apoio a esperava todos os dias no portão da escola e a mãe sempre a levava e conversava com ela passando algumas instruções relativas à alimentação e estado geral da aluna. Em algumas ocasiões, a mãe de AL01 orientou a professora de apoio a não permanecerem na sala, explicando que a filha não estava se sentindo bem. Assim, a professora de apoio a levava para a biblioteca onde passavam a tarde fazendo atividades individuais.

Na sala de aula, a professora regente pouco conversava com AL01 e AL02, somente a professora de apoio interagia com essas alunas. Os demais alunos também não se relacionavam com elas.

A AL01 conseguia realizar as atividades propostas pela professora regente, ela é alfabetizada, escreve e lê bem, segundo a professora de apoio, ela entende tudo na hora da explicação, porém no dia seguinte já esqueceu, então é preciso estar sempre voltando nas matérias anteriores.

Na hora do recreio a AL01 saía cinco minutos antes dos outros alunos, ia segurando no ombro da professora de apoio que a levava para o refeitório e ficava esperando sua merenda.

Na hora de ir embora a AL01 também não saía com os demais estudantes, ela saía cerca de dez minutos antes, segundo a professora isso é devido ao cuidado que ela tem para que a aluna não se machucasse ou os outros alunos esbarrassem nela e a derrubassem. 
Quanto à AL02 ela ia à escola de ônibus escolar e chegava sempre no mesmo horário, porém, ela não era frequente, faltava muito às aulas.

A AL02 possuía dificuldade para falar, não conversava em sala, não opinava em nada, interagia apenas com a AL01 e com a professora de apoio. Não conversava nem tão pouco brincava com os demais colegas.

Em dias de festividades, as estudantes não desciam para a quadra, ficavam em uma cadeira no alto da arquibancada assistindo tudo à distância.

Em sala de aula observou-se que ambas as alunas levantavam a mão querendo participar das atividades, porém não eram vistas.

As alunas ficavam a maior parte do tempo juntas, tanto na sala de aula quanto na hora do intervalo de recreio em que elas ficavam sentadas no refeitório.

Percebeu-se certo distanciamento entre as alunas e os demais alunos, não se presenciou, portanto nenhuma prática pedagógica, nem na sala de aula nem mesmo no recreio, algo que aproximasse as alunas dos demais estudantes.

A família da AL01 era muito presente na escola e estava sempre perguntando, dando sugestões e avaliando o comportamento dos profissionais que se relacionavam com a filha.

A família da AL02 é muito ausente, não participava de reuniões, e, a aluna falta muito às aulas, algumas vezes ela se sentiu mal na escola, os pais eram chamados, mas não compareciam.

\section{Formação Docente}

Um dos objetivos dessa pesquisa era compreender se as profissionais da educação participantes neste estudo se sentiam preparadas para trabalhar com alunos com NEE.

Pelos dados coletados percebeu-se certa insegurança por parte da PR1 que, apesar de afirmar se sentir preparada para lecionar para as alunas com NEE e que, inclusive, já trabalhou com pessoas com deficiências bem mais graves, atribui o bom andamento de suas aulas à presença da PA. Ressaltou que esta profissional está o tempo todo com as alunas para ajudá-las no que for preciso. Ela afirmou ainda que seria difícil trabalhar com as alunas com NEE se a PA não estivesse em sala, deixando claro também, que não é de sua responsabilidade dar assistência a essas alunas, pois a outra professora está em sala com elas o tempo todo: 
Eu me sinto preparada para trabalhar com essas alunas, porque tem outra professora o tempo todo com elas e ajuda em todo momento, ai dá pra desenvolver muita coisa porque ela está presente. Agora seria com mais dificuldade se ela não estivesse presente, se fosse eu sozinha pra essa quantidade de alunos e ainda tivesse que dar assistência pra elas (PR1).

A PR2 por sua vez, afirmou ter muita dificuldade em trabalhar com alunos com NEE quando não tem um professor de apoio em sala para auxiliá-la. "Eu tive muita dificuldade, pois não tinha professora acompanhante" (PR2).

A PA apesar de ser especializada em educação especial, afirmou ter tido muita dificuldade em trabalhar com a AL01, que possui sequelas de mielomeningocele. Ela diz que se sentia insegura quanto às reclamações de dores de cabeça e tinha dificuldades na hora das atividades diárias. "Não me sinto totalmente preparada porque tem deficiências muito difíceis de lidar. No caso da AL01 eu não sabia lidar com a "sonda" e por ela ser uma pré-adolescente nós duas tivemos dificuldades na hora de fazer a higiene dela" (PA).

Quanto à SP atribuiu o despreparo e a insegurança das educadoras à formação que tiveram. E que, a primeira coisa que os professores perguntam quando sabem que vão ter em sala um aluno com NEE é se terão professores de apoio:

\footnotetext{
Os professores não estão preparados porque muitos fazem certos cursos a distância e quando chegam percebem que a realidade é muito diferente. A primeira coisa que perguntam quando sabem que terão alunos deficientes [sic] em sala é se terão professores de apoio para ficar com esses alunos (SP).
}

Ao analisar as respostas das entrevistadas é interessante observar que de certa forma as professoras regentes se sentem seguras com a presença das alunas em sala, somente se também tiverem uma professora especializada em sala para ajudá-las, e de certa maneira acabam transferindo a instrução dessas alunas para a professora de apoio.

Corroborando essa ideia, Godofredo (1999) salienta a importância do preparo do professor mediante a diversidade:

\footnotetext{
A partir do movimento de inclusão, o professor precisa ter capacidade de conviver com os diferentes, superando os preconceitos em relação às minorias. Tem de estar sempre preparado para adaptar-se às novas situações que surgirão no interior da sala de aula (GOFFREDO, 1999, p. 68).
} 
Diante disso, conforme afirma Toledo e Martins (2009), a preparação do professor é muito importante para a inclusão desses alunos com NEE. Não basta somente ter boa vontade em recebêlos e ter a presença do professor de apoio, visto que, independente do seu preparo, esses alunos vão continuar chegando às escolas. Godofredo (1999) defendeu ainda que era preciso investir na formação docente para lidar com os alunos com NEE:

Precisamos, então, investir com seriedade na formação inicial e continuada dos profissionais da educação e, de forma mais específica, na formação do magistério para todos os níveis e modalidades educacionais. Esta formação, em todas as instâncias, precisa concordar com a política educacional brasileira vigente que prevê a inclusão/integração dos alunos com necessidades especiais no ensino regular e, também, com a oferta de serviços de Educação Especial para atender às necessidades educativas especiais (GOFFREDO 1999, p. 68, 69).

Diante das respostas coletadas observou-se também que há uma discrepância em relação às funções do professor especializado em sala para acompanhamento do aluno, uma vez que o Guia da Secretaria da Educação de Minas Gerais SEE/MG (2014) deixa claro que as atribuições desses profissionais são de trabalhar de forma colaborativa com o professor regente para promoverem uma educação de qualidade para os alunos com NEE:

Atuar de forma colaborativa com os professores da classe comum para a definição de estratégias pedagógicas que favoreçam o acesso do aluno com necessidades educacionais especiais ao currículo e a sua interação no grupo (MINAS GERAIS, 2014, p.21).

No entanto, ainda encontramos professores que se sentem inseguros com alunos com NEE em suas salas de aula. É comum, portanto esses docentes acabarem por transferir a educação desses alunos para o professor de apoio, por pensarem que esses professores especialistas estão mais preparados do que eles para trabalhar com esse alunado.

\section{Adaptações curriculares para os alunos com NEE}

As adaptações curriculares são modificações realizadas pelos professores com intuito de atender a todos os alunos, especialmente os que possuem NEE. Assim sendo, o docente precisa estar atento para a necessidade de adaptações tanto de atividades e materiais, quanto das avaliações, de modo que atendam as especificidades desse alunado. 
Nesse sentido, foi perguntado às professoras regentes e à professora de apoio se as alunas com NEE de sua sala de aula recebiam material adaptado ou atividades diferenciadas para cada aula. A PR1 e PR2 afirmaram que as alunas não precisavam de material adaptado nem de atividades diferenciadas, pois, com a ajuda da PA, elas "conseguiam" realizar "todas" as atividades propostas, sendo assim, as atividades para elas eram as mesmas da turma. No entanto, quando essas duas alunas com NEE não conseguiam alcançar a turma por estarem atrasadas em algum conteúdo ou por terem faltado muito, a PA leciona a matéria que foi dada pela PR1 para que as alunas possam acompanhar a classe:

\begin{abstract}
Eu não, o material que eu dou para os outros alunos eu dou pra elas também. Mas assim, quando acontece delas faltarem e ficar um pouquinho atrasadas ai a outra professora vai e dá aquelas [sic] coisas que estão atrasadas até chegar onde a gente está. Mas assim, todo material que é para a turma é para elas também, não é nada diferenciado (PR1).

Não, às vezes quando era multiplicação a PA adaptava alguma coisa, mas muito pouca coisa, comigo foi muito pouco. Era mais as minhas atividades (PR2).

Bom, é assim, eu vejo o que a professora vai dar na semana e ai eu vou adaptando para as alunas. A AL01 não precisa de material diferente, a AL02 não consegue copiar do quadro, apesar dela ser alfabetizada, ela demora demais e muitas vezes ela fica nervosa e começa a encolher e até a mão endurece. Então eu trago as atividades delas impressas. Quando não consigo trazer assim eu copio do quadro pra [sic] ela, pra ela não ficar atrasada com o caderno, porque pra fazer uma frase ela demora uns vinte minutos mais ou menos (PA).
\end{abstract}

Observou-se que há uma incoerência nas respostas da PR1 e PR2 em relação à resposta da PA, quando afirmaram que as alunas não precisavam de material diferenciado. Isso nos leva a refletir sobre o motivo da necessidade da AL02 não ficar "atrasada" perante os demais alunos da sala, e qual a razão da PA copiar do quadro por ela. Ora, torna-se pertinente perguntar: se a aluna está em processo de construção, o que ela irá aprender tendo um caderno copiado pela professora? A quem a aluna precisa mostrar um caderno completo? Outra questão relevante é: Por qual motivo as alunas devem acompanhar a classe? Não são todos diferentes? Logo, por que deveria estar no mesmo nível? Nesse sentido, Godoi (2006) argumenta que:

É muito importante que o professor tenha o máximo cuidado para observar cada aluno na rotina de sala de aula e se dedique a conhecer individualmente, de forma devida, a cada um, diante de suas prováveis dificuldades e habilidades, com o objetivo de ir ao encontro de suas reais necessidades de aprendizagem. Cada aluno é único e deve ser visto como tal, independentemente das diferenças que possa apresentar (GODOI, 2006, p. 83). 
Assim, é importante observar que cada aluno possui dificuldades e ritmos diferenciados de aprendizagem e que o aluno com NEE não é obrigado a acompanhar a classe. Diante disso, é interessante o professor compreender que ele deve valorizar cada progresso que o aluno conseguir realizar e não forçá-lo a acompanhar os demais estudantes, que também têm suas dificuldades e limitações.

\section{Sobre as adaptações relativas à avaliação das alunas com NEE}

Segundo Machado e Oliveira (2007), as adaptações curriculares relativas às avaliações são uma etapa complexa, pois envolve tanto o contexto escolar quanto o contexto da sala de aula. Essas adaptações curriculares avaliativas podem ocorrer por meio da "modificação das técnicas ou de instrumentos de avaliação, adaptando aos diferentes estilos e possibilidades de expressão dos alunos" (MACHADO; OLIVEIRA, 2007, p. 53-54). Diante disso professoras regentes e a professora de apoio foram questionadas sobre as avaliações das alunas, como eram realizadas e se as provas precisavam de adaptações.

As professoras responderam que as avaliações eram iguais às de todos os alunos, e que a PA acompanhava as alunas lendo a prova para elas. As professoras também explicaram que não era preciso adaptar as provas das alunas com NEE e que estas não precisavam de tempo adicional para a realização das mesmas:

A avaliação é a mesma que dou pra turma toda... a outra professora senta com elas e vai lendo atentamente com elas e elas vão falando as respostas que acham que é certa. Geralmente é o mesmo tempo (PR1).

As provas eram normais, eu perguntava pra professora de apoio se elas davam conta de fazer, elas faziam no tempo delas, outras para não deixar em branco a PA ajudava a fazer (PR2).

No entanto, ao perguntar à PA como eram realizadas as avaliações, obteve-se a seguinte resposta:

Elas precisam de um tempo maior para fazer, tem provas, por exemplo, a de português e matemática que elas levam dois dias para terminar. As provas da AL02 tem que ser toda de múltipla escolha, por que ela demora muito para escrever, então eu pego a prova que a professora vai dar e adapto para ela. Tem questões que elas não conseguem mesmo, então eu falo qual eu mudei e quais eu ajudei a fazer (PA). 
Diante das respostas da PR1 e PR2, percebeu-se um distanciamento com o que relata a PA ao dizer o oposto das colocações das duas professoras e com o que se presenciou no momento da observação em sala de aula, quando se constatou que: em uma avaliação as alunas demoraram cerca de 40 minutos a mais do que o restante da classe para terminar a prova. As alunas com NEE, de acordo com a PA, além de precisarem de um tempo adicional, têm que ter as provas adaptadas e, mesmo assim, ainda há questões que elas não conseguem resolver.

Machado e Oliveira (2007) afirmam que este modelo de avaliação tradicional mascara as reais dificuldades de aprendizagem não só dos alunos com NEE, como também dos demais alunos, criando um ambiente de exclusão. Além disso, estes autores defendem que este modelo de avaliação também acentua as dificuldades dos alunos que eles não teriam, caso fosse usado outro tipo de avaliação:

\footnotetext{
Abrir a possibilidade de se adaptar o sistema de avaliação para determinado aluno, em função de suas necessidades educacionais especiais, é uma das principais vias para se conseguir avaliar a aprendizagem com responsabilidade e profissionalismo, e poder então, promover os ajustes que se tornem necessários no processo de ensino, para garantir seu desenvolvimento educacional (MACHADO; OLIVEIRA, 2007, p 54).
}

Destarte, não é fazendo as avaliações pelos discentes com NEE que estaremos incluindo esse aluno. Trata-se, porém de avaliar com flexibilidade, fazendo as adaptações curriculares avaliativas necessárias para que o aluno com NEE tenha suas potencialidades não só respeitadas, mas também valorizadas, observando os seus estilos e ritmos de aprendizagem.

\section{Relação professora de apoio e alunas com NEE}

Ao observar a rotina das alunas na escola ficou evidente a dependência da AL01 em relação à PA. Verificou-se que a professora tinha muito receio que a aluna se machucasse e por isso havia um cuidado e/ou uma proteção excessiva em relação a esta aluna. Diante disso, as PR1, PR2, a SP e a PA, foram questionadas sobre como se dava o relacionamento entre a AL01 e a PA. A PR1 afirmou: "Já percebi essa dependência da AL01 com a PA, até conversamos sobre isso, afinal temos que preparar a aluna para o $6^{\circ}$ ano, e ai como vai ser, pode ser que não seja ela a professora de apoio dela no ano que vem". Por outro lado, as restantes educadoras afirmaram: 


\begin{abstract}
Dependência total, a aluna não aceita que outra pessoa fique com ela e os pais reforçam isso, só aceitam essa professora. Eles colocam a menina numa bolha, uma hora ela vai ter que crescer que conviver com outras pessoas, ela não conseguia dividir a PA nem com a AL02, a menina está crescendo numa bolha, não pode ter nenhum arranhão que a mãe já bem correndo (PR2).

A AL01 é muito dependente, eles não deixam a menina caminhar, ela tem suas limitações, mas também não é assim, ela não consegue ir ao banheiro sozinha, mas pegar seu lanche, sua água e assentar [sic] junto com os outros alunos, isso ela pode fazer (...) há uma superproteção tanto da PA quanto da família. Qualquer coisa que acontece a mãe vem correndo reclamar, isso é muito prejudicial. Ela é uma criança e toda criança machuca, estamos educando para que eles sejam sujeitos autônomos e ela precisa se desenvolver $(S P)$.

Olha ela é muito dependente, só quer ficar comigo, anda escorada em mim o tempo todo. Eu incentivo a independência dela sabe, por outro lado, tenho muito medo dela se machucar, essa escola é muito apertada, e se os outros alunos esbarram nela? Eles correm muito e se atropelam essa menina? Então eu saio com ela sempre cinco minutos antes dos alunos pra [sic] evitar isso (PA).
\end{abstract}

Sendo assim, observou-se uma insegurança da PA ao sentir "medo" da aluna se machucar, por isso ela a cercava de cuidados excessivos com o intuito de protegê-la. Entretanto, agindo desta forma, a PA além de excluir a aluna da convivência com os demais alunos, reforça as limitações da estudante ao percebê-la como incapaz de realizar atividades básicas, o que, segundo a SP, ela conseguia fazer. Mantoan (2009) afirma que o docente precisa mudar o foco das limitações para as potencialidades desses alunos:

\begin{abstract}
A inclusão da pessoa com deficiência no sistema educacional, portanto, exige uma mudança de foco, desloca-se o foco da limitação para a potencialidade humana, do desrespeito às diferenças para a valorização dessas diferenças. Esse movimento dá visibilidade à pessoa em questão e, por conseguinte, aos empecilhos sociais que ela enfrenta, em sua vida cotidiana, para se colocar na sociedade (MANTOAN, 2009. p. 71).
\end{abstract}

Minetto (2012) salienta, porém, que é compreensível que o docente sinta "medo" diante do diferente, pois o despreparo do professor envolve não só os aspectos pedagógicos como também os emocionais, portanto, sentir insegurança diante do "novo" é algo comum.

Essa mesma autora enfatiza a essencialidade da formação continuada de saberes, para que estes conhecimentos advindos desta formação venham favorecer as reais necessidades impostas pela educação inclusiva. "O professor precisa identificar suas percepções sobre sua prática pedagógica para buscar soluções conscientes nas áreas que estejam defasadas, sejam ela teóricas, práticas ou relacionais" (MINETTO, 2012, p. 46). 
Entretanto, Minetto (2012) também reforça a importância dos cursos de formação e especialização, atenderem as especificações da educação inclusiva, pois esses profissionais se deparam constantemente com desafios que requerem novos saberes, e para que os cursos de formação atendam a essas exigências do cotidiano destes profissionais. Acentua ainda que tais cursos devem conter professores, mestres e doutores que dominem não só a teoria, mas também a prática da educação inclusiva (MINETTO, 2012, p. 46). Assim sendo, para que haja uma nova concepção de educação na perspectiva da educação inclusiva é preciso ter profissionais bem formados para compreender a necessidade da diversidade na prática educativa.

\section{CONSIDERAÇÕES FINAIS}

Ao desenvolver esta pesquisa procurou-se compreender como ocorria o processo de inclusão de duas alunas com NEE em uma sala de aula comum de uma escola pública. Buscava-se também conhecer as práticas dos docentes e se estas condiziam com o que estudamos no curso de formação de professores.

Deparamos com a ausência de materiais simples, porém, essenciais para o desenvolvimento das atividades escolares das alunas com NEE. Percebeu-se que não havia móveis adequados nem tão pouco eram realizadas as adaptações curriculares e de materiais para atender as necessidades dessas educandas.

Percebemos que as alunas com NEE em questão muitas vezes passavam despercebidas pela escola, quando em dias de apresentações teatrais elas permaneciam sozinhas no alto de uma arquibancada com a mão levantada querendo interagir com a plateia e com os apresentadores do teatro, no entanto, todos se divertiam no interior da quadra e não as viam. Diante disso, procurouse entender por que isso acontecia, por que ainda hoje em uma escola que deveria acolher a todos, distanciava alunas com NEE com o intuito de "proteger", mas protegê-las de quem e por qual motivo. Não deviam elas ser participantes ativas no contexto escolar? Participando das festividades junto aos demais colegas? Entende-se então, que a inclusão ainda causa insegurança nos professores, que sentem medo de errar e assim protegem para que as discentes com NEE não se machuquem fisicamente. 
Contudo, entende-se então que a inclusão de uma forma equânime e com igualdade de oportunidades, nesta escola, ainda não se concretizou de fato, pois incluir não é somente colocar alunos juntos, integrá-los em um mesmo espaço, nem tão pouco segregá-los do convívio com os demais colegas. Incluir vai muito além do integrar, é respeitar e valorizar o outro com suas diferenças e oferecer oportunidades para que construam conhecimentos e desenvolvam com autonomia.

\section{REFERÊNCIAS}

ABCMED, 2013. Sofrimento fetal ou hipóxia neonatal: como é? Disponível em: $<$ http://www.abc.med.br/p/saude-da-crianca/513044/sofrimento-fetal-ou-hipoxia-neonatal-comoe.htm>. Acesso em: 05 nov. 2016.

AGUIAR, Marcos J.B.; CAMPOS, Ângela S.; AGUIAR, Regina A.L.P.; LANA, Ana Maria A.; MAGALHÃES, Renata L.; BABETO, Luciana T. Defeitos de fechamento do tubo neural e fatores associados em recém-nascidos vivos e natimortos. Jornal de Pediatria,v. 79, n.2, 2003.

Disponível em: $<$ http://www.scielo.br/scielo.php?pid=S0021-

$75572003000200007 \&$ script $=$ sci arttext\&tlng=pt $>$ acesso em: 10 out. 2016.

ASSIS, Caroline Penteado de; MARTINEZ, Cláudia Maria Simões. A inclusão escolar de alunos com sequelas de mielomeningocele. Caderno de Terapia Ocupacional. UFSCar, São Carlos, v. 19, n. 3, p. 307-322, 2011.

CARDOSO, Silvia Helena. Hidrocefalia. Cérebro \& Mente. n. 2, 2016. Disponível em: < http://www.cerebromente.org.br/home_i.htm>. Acesso em: 21 de set. 2016.

CARNEIRO, Moaci Alves. $O$ acesso de alunos com deficiência às escolas comuns. Petrópolis: Vozes, 2007, 147 p.

CARVALHO, Rosita Edler. Educação Inclusiva: a reorganização do trabalho pedagógico. Porto Alegre: Mediação, 2008, 152 p.

CARVALHO, Rosita Edler. Educação Inclusiva: com os pingos nos “is”. Porto alegre. Mediação 2004, 17 p.

CHIZZOTTI, Antônio. Pesquisas em Ciências Sociais. São Paulo, 11 ed. São Paulo: Cortez, 2011 $164 \mathrm{p}$.

FURLAN, Márcia Lúcia de Souza; CALIRI, Maria Helena L.; DEFINO, Helton L. Intestino neurogênico. Guia prático para pessoas com lesão medular. USP. Ribeirão Preto: coluna/columnc 2005, P. 151, 157. Disponível em< 
< http://www.plataformainterativa2.com/coluna/html/revistacoluna/volume4/vol_04_03_151157_2005.pdf> acesso em 31 out. 2016.

FURTADO, Maria Renata silva. As armadilhas da Educação Inclusiva: um estudo de caso em um: escola da Rede Municipal de Educação de Belo Horizonte. 2007. 124 p. Dissertação (Mestrado)Programa de Pós-Graduação em Psicologia, Pontifícia Universidade Católica de Minas Gerais, Belo Horizonte, 2007.

GODOFREDO, Vera Lúcia Flor Sénéchal de. Como formar professores para uma escola inclusiva? Salto para o Futuro: Educação Especial: tendências atuais. Secretaria de Educação a Distância. Brasília: Ministério da Educação, SEED, 1999, p. 67, 72. Disponível em: http://livros01.livrosgratis.com.br/me002692.pdf> acesso em 29 out. 2016.

GODOI, Ana Maria de. Educação infantil: saberes e práticas da inclusão: dificuldades de comunicação e sinalização: deficiência física. 4. Ed. Associação de Assistência à Criança Deficiente AACD. Brasília: MEC, Secretaria de Educação Especial, 2006. 98 p.

GOLDENBERG, Mirian. A arte de pesquisar. 11 ed. Rio de Janeiro: Record, 2009. 107 p.

GREGGIO, Samuel; COSTA Jaderson Costa da. Crises convulsivas associadas à hipóxia neonatal e । potencial uso terapêutico do neuropeptídeo NAP. Scientia Medica, Porto Alegre, v. 18, n. 1, p. 45 53, jan./mar. 2008. Disponível em<

http://revistaseletronicas.pucrs.br/ojs/index.php/scientiamedica/article/viewFile/2430/2812> acesso em 05 de Nov. 2016.

MACHADO, Katia da Silva; OLIVEIRA, Eloiza de. Adaptações Curriculares: caminho para uma educação inclusiva. IN: Rosana Glat. Educação Inclusiva: Cultura e cotidiano escolar. Rio de Janeiro: 7letras, 2007, p. 40, 56.

MANTOAN, Tereza Egler. As Pessoas com deficiência: dos paradigmas educacionais às antropologias Subjacentes. IN: Elizabete Cristina Costa-Renders. Educação e Espiritualidade: pessoas com deficiências, sua visibilidade e emergência. São Paulo: Paulus, 2009, p. 59, 100.

LAKATOS, Eva Maria; MARCONI, Marina de Andrade. Fundamento da Metodologia Cientifica. $7^{\circ}$ Ed, São Paulo, Atlas, 2010. 277 p.

MEDEIROS, Daiane Lazzeri; PACHECO, Sheila Cristina da silva; BOBBIO, Tatiana Godoy; COELHO, Jerusa Jordão Lilian; RIES, Gerdi Kittel. Tratamento para deformidades nos pés em crianças com paralisia cerebral. Pediatria Moderna. Abr. 2013, Vol. 49, n 4. Disponível em < http://www.moreirajr.com.br/revistas.asp?fase=r003\&id_materia=5375> acesso em 31 out. 2016.

Secretaria de Estado de Educação de Minas Gerais. Guia de Orientação da Educação Especial na rede estadual de ensino de Minas Gerais: versão 3. Minas Gerais: SEE/MG, 2014, 35 p. Disponível em:<http://seeensinoespecial.educacao.mg.gov.br/>._Acesso em 19 set. 2016. 
MINETTO. Maria de Fátima. Adaptações curriculares: uma necessidade na escola inclusiva. In: Maria de Fátima Minetto. Currículo na Educação Inclusiva: entendendo este desafio. Editora Intersaberes. 2012. Livro Eletrônico.

PORTAL BRASIL. Dados do censo escolar indicam aumento de matrícula de alunos com deficiência. [S.1.]: Portal Brasil, 2015. Disponível em< http:/www.brasil.gov.br/educacao/2015/03/dados-do-censo-escolar-indicam-aumento-dematriculas-de-alunos-com-deficiencia $>$ acesso em set.2016.

RODRIGUES, Olga Maria Piazentin Rolim. Educação especial: história, etiologia, conceitos e legislação vigente. In: Olga Maria Piazentim Rolim Rodrigues, Elisandra André Maranhe. Práticas em educação especial e inclusiva na área da deficiência mental. v. 12. Vera Lúcia Messias Fialh Capellini. (Org.). Bauru, 2008. Disponível em:<

http://www2.fc.unesp.br/educacaoespecial/material/Livro2.pdf $>$ acesso em: 15 de set. 2016.

TOLEDO, Elizabete Humai de; MARTINS, João Batista. A atuação do professor diante do processo de inclusão e as contribuições de Vygotsky. In: CONGRESSO DE EDUCAÇÃO EDUCERE, 9, 2009, Rio de Janeiro. Encontro de Sul Brasileiro de Psicopedagogia... Rio de Janeiro: PUCPR, 2009. P. 4.126 - 4.138. Disponível em: < http://www.pucpr.br/eventos/educere/educere2009/anais/pdf/3298_1675.pdf acesso em 15 de ago. 2016.

\title{
A CASE STUDY OF STUDENTS WITH NEUROMOTIVE DISABILITIES: AN ANALYSIS OF THEIR SCHOOL EXPERIENCE IN A REGULAR EDUCATION INSTITUTION FROM THEIR TEACHERS' PERSPECTIVE
}

\begin{abstract}
The present work seeks to understand the school life of two students with neuromotor disability, from the perspective of the educational professionals that support them at a mainstream primary school in the city of Esmeraldas, Minas Gerais. The rationale behind the subject's choice was our interest in understanding how primary school professionals deal with the challenges work with pupils with special educational needs present, in particular, one pupil that had suffered from myelomeningocele and another one had suffered perinatal hypoxia. To subsidize our study a number of readings, observations and interviews were conducted. Education professionals who maintained close contact with these pupils were selected. This small-scale study showed that education professional are ill-equipped and insecure when working with children with these specific limitations, besides revealing their "exclusion" in an environment that should belong to everyone.
\end{abstract}

Keywords: Inclusive education. Teaching Practice. Support Teacher. 


\title{
UN ESTUDIO DE CASO DE ESTUDIANTES CON DISCAPACIDADES NEUROMOTRICES: UN ANÁLISIS DE SU EXPERIENCIA ESCOLAR EN UNA INSTITUCIÓN DE EDUCACIÓN REGULAR DESDE LA PERSPECTIVA DE SUS MAESTROS
}

\begin{abstract}
RESUMEN
El presente trabajo busca comprender la vida escolar de dos estudiantes con discapacidad neuromotora, desde la perspectiva de sus maestros y asistentes, en una escuela primaria municipal en la ciudad de Esmeraldas, Minas Gerais. La elección del tema se debió al interés en comprender cómo los maestros de la Escuela Primaria trabajé con los desafíos de dos estudiantes con necesidades educativas especiales, uno de los cuales tenía secuelas de mielomeningocele y el otro secuelas de hipoxia perinatal. Para este estudio se realizaron inúmeras lecturas, observaciones y entrevistas. Se seleccionaron profesionales de la educación que mantuvieron un contacto cercano con estos estudiantes. De este estudio queda clara la falta de preparación y la inseguridad de los profesionales para trabajar con niños con estas limitaciones, así como expone su "exclusión" en un entorno que debería ser de todos.
\end{abstract}

Palabras clave: Educación inclusiva. Práctica docente. Profesor de apoyo.

Submetido em: abril de 2020.

Aprovado em: abril de 2020.

Publicado em: abril de 2020. 